\title{
E-Policy, Law and Governance: Minitrack introduction
}

\author{
Marijn Janssen \\ School of Technology, \\ Policy and Management \\ Delft University of \\ Technology \\ Marijnj@tbm.tudelft.nl
}

\author{
Robert Krimmer \\ Department of Production \\ Management \\ Vienna University of \\ Economics and Business \\ Administration, Austria \\ Krimmer@wu-wien.ac.at
}

\author{
Terrence A. Maxwell \\ School of Information \\ Science and Policy \\ State University of New \\ York, Albany, NY, USA \\ tamaxwell@hvc.rr.com
}

This minitrack is a direct successor to the previous epolicy minitrack in the e-government cluster. During the last years the fields of e-governance and e-law has increasingly been receiving attention, and as a result has been added to this minitrack.

Papers in this minitrack address how public policies, laws and governance are related to the use and development of information and communication technologies (ICT) both in government and in society at large. Government policies and legislation can create the technological environment and the necessary boundaries for e-government and e-democracy applications and services. At the organizational level, this includes aspects of equal access rights, privacy protection, public safety, security, and information dissemination. In the context of government information systems and at the infrastructure level, it encompasses the introduction of national ID cards, central citizen registries, data centers and a trusted infrastructure. Policy issues and their analysis pertain to the digital divide, infrastructure development, open source, standards and educational uses of ICT. Epolicies related to national development are also addressed by this minitrack.

Governance refers to the system of directing and controlling the actions, affairs, policies and functions of a political unit, organization, or nation. Egovernance is getting more attention, as it has the potential to ensure that the spending of public money is done in an effective and efficient way. This would create a dynamic, creative public sector capable of anticipating on and being open, responsive, democratic and accountable for their action, facilitating customer preferences.

The seven papers in this minitrack are clustered into two sessions. In the first session, the first paper Legal and Ethical Implications of Employee Location Monitoring by Gundars Kaupins, and Robert Minch analyze legal and ethical implications of employee location monitoring. This is an excellent paper capturing the interplay between technology-enabled issues like monitoring, privacy, security, repudiation and law.

In the second paper, Global Copyright Protest? A Comparison of DeCSS Posting in the People's Republic of China, Hong Kong, and the European Union, Kristin R. Eschenfelder, Anuj C. Desai, Ian Alderman, Joanna Sin, and Shen $\mathrm{Yi}$ explores the posting of a computer program able to circumvent encryption protection of DVDs in a number of countries outside the USA.

Lack of workable strategic information system planning (SISP) and new theoretical models of SISP are examined in Models for U.S. State Government Strategic Information Systems Planning (SISP) by Donna Dufner, Lyn M. Holley, and B.J. Reed.

The second session starts with Legal Issues in Agents for Electronic Contracting authored by Irene Kafeza1, Eleanna Kafeza, Dickson K.W. Chiu. The authors present a legal framework to analyze legal issues arising from the use of intelligent, software-based agents.

The second paper in this session Business Compliance to Changing Privacy Protections by Natasha Dubauskas investigates Australia's transformation from self-regulation to legislation.

The third paper Information Policy, Data Mining, and National Security: False Positives and Unidentified Negatives authored by Terrence Maxwell, examines assumptions about the relationship between national security databases and information privacy concerns when goal success is not known.

The last paper of the second session Organizational Determinants of Internally Perceived Website Effectiveness in State Health and Human Service Agencies by David H. Coursey, Eric W. Welch, and Sanjay K. Pandey examines possible predictors of perceived website effectiveness. 